\title{
PAPEL DOS NUTRIENTES NA PEROXIDAÇÃO LIPÍDICA E NO SISTEMA DE DEFESA ANTIOXIDANTE
}

\author{
ROLE OF NUTRIENTS ON LIPID PEROXIDATION AND ANTIOXIDANT DEFENSE SYSTEM
}

Helio Vannucchi' ${ }^{1}$, Emilia AM Moreira², Daniel Ferreira da Cunha³, Márcia V. M. Junqueira-Franco', Mônica M. Bernardes ${ }^{1}$, Alceu A. Jordão-Jr'

\begin{abstract}
${ }^{1}$ Divisão de Nutrição Clínica do Departamento de Clínica Médica da Faculdade de Medicina de Ribeirão Preto - USP. ${ }^{2}$ Departamento de Nutrição - Universidade Federal de Santa Catarina - SC. ${ }^{3}$ Nutrologia - Faculdade de Medicina do Triângulo Mineiro - Uberaba MG CorRESPONDÊNCIA: Dr. Helio Vannucchi - Divisão de Nutrição Clínica do Depto de Clínica Médica da Faculdade de Medicina de Ribeirão Preto - USP - Av. Bandeirantes, 3900 - 14049-900 Ribeirão Preto/SP - Email: hvannucc@fmrp.usp.br
\end{abstract}

VANNUCCHI $\mathrm{H}$ et al. Papel dos nutrientes na peroxidação lipídica e no sistema de defesa antioxidante. Medicina, Ribeirão Preto, 31: 31-44, jan./mar. 1998.

RESUMO: Espécies reativas de oxigênio são formadas durante o metabolismo aeróbico e podem danificar lipídios, proteínas, carboidratos e o DNA. Essas reações, potencialmente deletérias, são controladas por um sistema de antioxidantes enzimáticos e não enzimáticos, que eliminam os próoxidantes e "varrem" os radicais livres. Esta revisão mostra o papel de alguns nutrientes na peroxidação lipídica e no sistema de defesa antioxidante. Enfatizam-se os mecanismos que levam ao dano oxidativo e sua proteção, assim como as implicações na saúde humana.

UNITERMOS: Antioxidantes. Nutrição. Perioxidação Lipíca. Radicais Livres.

\section{INTRODUÇÃO}

Os primeiros estudos a respeito de radicais livres se deram por volta de 1924. No entanto, só nos anos setenta, começaram a surgir trabalhos, relatando a importância dos radicais livres para os seres vivos, particularmente os aeróbicos. Os principais estudos relacionaram sua atuação junto a aspectos da Biologia Celular e Molecular, Fisiologia e Patologia Humana ${ }^{(1)}$.

A importância dos radicais livres no metabolismo celular vem se tornando clara, em função de intensa investigação em vários campos, incluindo estudos da peroxidação lipídica, dos sistemas de oxidorredutase e no papel da superoxidodismutase. O interesse por radicais livres e antioxidantes tem se intensificado ultimamente, pelo possível papel dessas substâncias na patogênese de diversas doenças. Assim, estudos sobre os sistemas de oxirredução, envolvendo a peroxidação lipídica, espécies oxidantes, toxinas ambientais (xenobióticos) mediadas por radicais livres, e a relação desses sistemas com a arteriosclerose, inflamação, diabetes, câncer e outras doenças, bem como uma desejada proteção efetuada pelos antioxidantes, tem levado inúmeros autores a se dedicarem ao assunto, procurando estabelecer uma segura base fisiopatológica para os vários processos. Na Tabela I, são listadas algumas condições nutricionais, associadas com o dano oxidativo, provocado por radicais livres.

\section{O QUE É UM RADICAL LIVRE?}

O termo radical livre é freqüentemente usado para designar qualquer átomo ou molécula com existência independente, contendo um ou mais elétrons não pareados, nos orbitais externos. Um elétron não pareado é aquele que ocupa um orbital atômico ou molecular isoladamente ${ }^{(2)}$. 


\begin{tabular}{ll}
$\begin{array}{l}\text { Tabela I - Algumas condições nutricionais associa- } \\
\text { das com dano oxidativo }\end{array}$ \\
\hline Câncer & $\begin{array}{l}\text { Alcoolismo } \\
\text { Pancreatite }\end{array}$ \\
Artrite & $\begin{array}{l}\text { Dermatite } \\
\text { Consumo elevado de } \\
\text { ácidos graxos }\end{array}$ \\
Doenças Inflamatórias & Hipertensão \\
Aterosclerose & Sobregarga de Ferro \\
Diabetes & Deficiência de Selênio \\
Doença Renal & Isquemia e Reperfusão \\
Envelhecimento & Deficiência de Vitamina E \\
\hline
\end{tabular}

A presença de um ou mais elétrons não pareados determina uma atração para um campo magnético e, algumas vezes, torna a substância altamente reativa $^{(2,3)}$.

Radicais livres podem ser formados pela perda de um único elétron ou pelo ganho de um elétron de uma substância não radical. Eles podem ser formados quando uma ligação covalente é quebrada e um elétron de cada um dos pares permanece em cada átomo, em processo chamado fissão homolítica. A energia necessária para dissociar a ligação covalente pode ser fornecida pelo calor, radiação eletromagnética ou outras fontes ${ }^{(2,5)}$.

A grande maioria dos radicais livres possui como característica uma meia-vida muito curta, indo de minutos a nanossegundos, sendo capazes de reagir rapidamente com vários compostos ou atingir alvos celulares, como as membranas.

\section{QUAIS SÃO OS RADICAIS LIVRES?}

Entre as várias espécies de radicais livres estão principalmente as derivadas do oxigênio e os metais de transição. As principais espécies de radicais livres derivadas do oxigênio, juntamente com sua meia-vida, estão listadas na Tabela II.

Oxigênio e seus derivados - A molécula de oxigênio, como ocorre naturalmente, com certeza, se qualifica como radical: ela tem dois elétrons não pareados, cada um deles localizado em diferentes orbitais. Esses dois elétrons têm a mesma rotação espinorial, rotação paralela, sendo este o estado mais estável do oxigênio.
O oxigênio é um bom agente oxidante, entendendo-se por oxidação a perda de elétrons por um átomo ou molécula; (conversão do átomo de sódio em íon $\mathrm{Na}^{+}$) e, por redução, o ganho de elétron por um átomo ou molécula (conversão do cloro em íon $\mathrm{Cl}^{-}{ }^{(4)}$.

Um oxidante age como receptor de elétrons das moléculas que oxida (como o cloro) enquanto que um agente redutor é um doador de elétrons.

Entretanto, um par de elétrons, em um orbital de energia de um átomo ou molécula, não atende necessariamente o critério, somente quando eles tiverem orientação oposta. Isso impõe uma condição de restrição à transferência de elétrons, o que tende a fazer o oxigênio aceitar os elétrons, um de cada vez, contribuindo o fato de que o oxigênio reage vagarosamente com muitos não radicais. Formas mais reativas de oxigênio, como o oxigênio singleto, podem ser geradas por absorção de energia. Nas formas de oxigênio singleto, a restrição de rotações dos elétrons é removida e a habilidade de oxidação está grandemente aumentada.

Se um elétron é adicionado ao oxigênio no estado fundamental forma-se o radical superóxido $\mathrm{O}_{2}$-. A adição de mais um elétron resultará em $\mathrm{O}_{2}{ }_{2}^{2-}$, o íon peróxido, que não é um radical. Usualmente, em sistemas biológicos, o produto da redução por dois elétrons do oxigênio é o rperóxido de hidrogênio se mistura com óxido de hidrogênio $\left(\mathrm{H}_{2} \mathrm{O}_{2}\right)$, e o produto da redução com 4 elétrons é a água ${ }^{(4)}$.

Ozônio - É produzido por fotodissociação do oxigênio molecular em átomos de oxigênio, os quais reagem com as moléculas de oxigênio, sendo um agente oxidante mais potente que o oxigênio no estado fundamental ${ }^{(4)}$. 
Metais de transição - Todos os metais da primeira fileira da tabela periódica contêm elétrons não pareados, o que os qualifica como radicais (com exceção do zinco). $\mathrm{O}$ fator de maior significado, em relação ao seu estado reativo, são suas valências variáveis, o que permite modificações do potencial de oxidação, envolvendo um elétron. São eles: ferro, cobre, vanádio, cromo, manganês, cobalto, níquel e molibdênio. Por exemplo: o ferro tem três valências: ferro atômico, ferro II, ferro III e o ferro IV. Em solução, na presença de ar, o ferro III é o mais estável, enquanto que os sais de ferro II são redutores fracos e os compostos ferris são poderosos agentes oxidantes. Se uma solução de sais de ferro II é deixada exposta ao ar, ela é vagarosamente oxidada ao estado de ferro III. Esta é uma oxidação por um elétron, e o oxigênio, dissolvido na solução, é reduzido a radical superóxido $\mathrm{O}_{2}^{(4,6)}$.

O cobre tem duas valências mais comuns, cobre I e cobre II. A diferença de um elétron permite ao cobre participar de reações de radicais. Sob condições adequadas, os sais de cobre poderão aceitar elétrons, ou doar elétrons ao radical superóxido.

O zinco, pelo contrário, tem somente uma valência e não promove reações com radicais. Tem sido sugerido que o zinco pode inibir algumas reações de radicais in vivo, deslocando outros metais de transição, como o ferro do local da ligação onde estejam promovendo as reações ${ }^{(4,6)}$.

\section{Reação de Fenton}

Uma mistura de peróxido de hidrogênio e um sal de ferro II reage com muitas moléculas orgânicas. Essa reatividade é devida, principalmente, à formação do radical chamado hidroxila. Traços de ferro III podem reagir $\mathrm{H}_{2} \mathrm{O}_{2}$. Assim, a mistura de um sal de ferro e peróxido de hidrogênio, (o que, certamente, forma em sistema biológico) pode promover toda uma série de reações como radicais ${ }^{(2)}$.

Outros Radicais Livres - Elétrons não pareados podem estar associados com uma variedade de outros átomos, por exemplo: radicais com enxofre central (difenil, dissulfeto), radicais com carbono central (triclorometil), radicais com nitrogênio central (fenildiazina) e radicais com fósforo central ${ }^{(4)}$.

\section{PROTEÇÃO CONTRA OS RADICAIS LIVRES}

Os radicais livres (especialmente $\mathrm{O}_{2}^{-}$) e outras espécies reativas de oxigênio $\left(\mathrm{H}_{2} \mathrm{O}_{2}\right)$ são continua- mente produzidos in vivo. Conseqüentemente, os organismos desenvolvem sistemas antioxidantes de defesa, para proteção, como também sistemas de reparação, que previnem o acúmulo de moléculas alteradas por oxidação ${ }^{(4,7,8)}$. Na Tabela III, são exemplificados alguns componentes do sistema de proteção antioxidante. Entre tais antioxidantes, destacamos alguns nutrientes (vitamina $\mathrm{E}, \beta$-caroteno), várias enzimas e seqüestradores não enzimáticos, que fazem um papel protetor crítico quanto aos danos oxidativos, atuando sempre em sinergismo, localizados dentro das células ou na circulação sangüínea ${ }^{(9,10)}$. Neste artigo, destacamos, principalmente, os nutrientes antioxidantes, enfocando o papel da dieta na obtenção desses nutrientes com a conseqüente proteção contra os radicais livres. O termo "antioxidante" é amplamente utilizado. Freqüentemente, o termo é limitado aos inibidores da peroxidação lipídica, como $\alpha$-tocoferol. Portanto, radicais livres, gerados in vivo, danificam muitas outras estruturas, além da de lipídios, incluindo proteínas, DNA e pequenas moléculas. Uma definição ampla para o termo antioxidante é: "uma substância que, quando presente em baixas concentrações, comparada ao substrato oxidável, deleta ou previne, significativamente a oxidação desse substrato". O termo "substrato oxidável" inclui várias substâncias, encontradas tanto em alimentos como em tecidos vivos, incluindo proteínas, lipídios,carboidratos e DNA. Esta definição enfatiza a importância do alvo e a fonte do dano oxidativo na caracterização do antioxidante. A importância de vários antioxidantes in vivo, hoje amplamente estudados, depende de onde, quando e como os radicais livres são gerados. Os antioxidantes também são de grande interesse na indústria alimentícia, onde são freqüentemente adicionados aos alimentos, a fim de prevenir os processos de rancidificação e manter a sua qualidade nutricional ${ }^{(11)}$.

\section{Proteção por Enzimas}

Existe um sistema de proteção contra o peróxido de hidrogênio, exercido pelas enzimas catalase e peroxidase. Dois tipos de enzimas existem para a remoção do peróxido de dentro das células (oxidação ${ }^{(4,8,12,13)}$. As catalases catalisam a reação:

$$
2 \mathrm{H}_{2} \mathrm{O}_{2}-2 \mathrm{H}_{2} \mathrm{O}+\mathrm{O}_{2}
$$

e as peroxidases segundo a reação:

$$
\mathrm{SH}_{2}+\mathrm{H}_{2} \mathrm{O}_{2}-\mathrm{S}+2 \mathrm{H}_{2} \mathrm{O}
$$


Tabela III - Componentes do sistema de proteção antioxidante

ANTIOXIDANTES NÁO ENZIMÁTICOS

- Glutationa

- Ubiquinona (Coenzima Q)

- Ácido úrico

- Bilirrubina

- NADPH e NADH

- Flavonóides

- Vitamina C

- Vitamina E

- $\beta$-caroteno

- Licopeno

PROTEÍNAS LIGADORAS DE METAIS

- Ceruloplasmina (cobre)

- Metalotioneína (cobre)

- Albumina (cobre)

- Transferrina (ferro)

- Ferritina (ferro)

- Mioglobina (ferro)

ANTIOXIDANTES ENZIMÁTICOS

- Superóxido Dismutase (SOD)

- Catalase

- Glutationa Peroxidase (GPx)

O oxigênio produzido pelas catalases é o estável e não o singleto.

Catalases - A catalase é uma hemeproteína citoplasmática, presente nos principais órgãos, estando especialmente concentrada no fígado e eritrócitos. Sua atividade depende do NADPH. Esta enzima também desempenha um importante papel no metabolismo do álcool.

Glutationaperoxidase - A enzima glutationa peroxidase catalisa a redução dos hidroperóxidos pela glutationa reduzida (GSH), levando à formação de glutationa oxidada (GSSG) e água. Esse processo catalítico é diretamente dependente da redução da glutationa oxidada pela glutationa redutase. A ação da glutationa peroxidase, mantendo a continuidade do processo de redução da glutationa reduzida, assim como sua subseqüente regeneração, via glutationa redutase, tem levado muitos pesquisadores a sugerirem a administração de tióis, como a $\mathrm{N}$-acetil-cisteína ou a própria glutationa, no sentido da manutenção dos níveis adequados de glutationa, como forma de proteção antioxidante.
Superóxido Dismutase - Em 1968, descobriu-se que uma proteína do eritrócito era capaz de remover cataliticamente os radicais superóxidos e, então, essa função ficou identificada como a da enzima superóxido dismutase ${ }^{(4,14)}$. A SOD é uma metaloenzima que, em sistemas eucarióticos, possui cobre, zinco e manganês e nos procarióticos contém ferro e manganês. As diferentes formas de SOD catalisam a mesma reação, a de dismutação do radical superóxido:

$$
\mathrm{O}_{2^{-}}+\mathrm{O}_{2}^{-}+{ }_{2} \mathrm{H}^{+} \text {------ } \mathrm{H}_{2} \mathrm{O}_{2}+\mathrm{O}_{2} \text { (estável) }
$$

No estudo realizado em nosso laboratório, onde ratos foram submetidos à nefrectomia subtotal, alimentados com dieta deficiente em vitamina E, observou-se um aumento da superóxido dismutase eritrocitária, provavelmente representando um mecanismo de defesa contra maior produção de radicais livres ${ }^{(15)}$.

\section{PAPEL DA DIETA NA PREVENÇÃO CONTRA RADICAIS LIVRES}

O papel da dieta sobre o efeito deletério dos radicais livres varia, consideravelmente, com o tipo de organismo testado, a idade, o estado fisiológico e a dieta ingerida ${ }^{(16)}$. A toxicidade de oxigênio é influenciada pela presença, na dieta, de diferentes quantidades de vitaminas A, E, C, carotenóides, ferro, selênio, enzimas e ácidos graxos polinsaturados ${ }^{(17,21)}$.

Assim, uma dieta contém um grande número de ambos, antioxidantes e pró-oxidantes. A quantidade relativa de antioxidantes e pró-oxidantes, na dieta, pode influenciar a susceptibilidade de um indivíduo em desenvolver "stress" oxidativo. O "stress" oxidativo pode ser causado pelo desbalanço nutricional devido à deficiência de antioxidantes, excessiva quantidade de pró-oxidantes, ou ambas ${ }^{(22,23)}$.

A interação entre micronutrientes indica que há necessidade de uma ingestão ideal para todos os nutrientes que são oxidantes, simultaneamente, pois, em caso de uma ingestão marginal de um deles, pode ocorrer subseqüente decréscimo na bioatividade do outro micronutriente essencial, ainda quando são consumidos níveis recomendados ${ }^{(24)}$. Acredita-se que, mesmo na presença de grande número de mecanismos potentes de defesa antioxidante, dentro das células, muitas vezes, os fatores oxidantes podem superar tais defesas e determinar lesões teciduais por meio das membranas lipídicas de células e organelas, a desnaturação funcional (enzimas) de proteínas estruturais, lesões mutagênicas ou letais dos ácidos nucléicos e a desnaturação de componentes polissacarídeos de componentes do interstício de membranas basais ${ }^{(25,26)}$. 


\section{Proteção por Pequenas Moléculas}

Pequenas moléculas podem exercer efeito antioxidante, quer agindo diretamente na neutralização dos radicais livres, quer participando indiretamente de sistemas enzimáticos com esta função. São elas: vitamina $\mathrm{C}$, glutationa, ácido úrico, vitamina $\mathrm{E}$, selênio e carotenoídes $(4,7,8,24,25,27,28,29)$.

Vitamina E e a peroxidação lipídica - Os radicais livres causam lesões em praticamente todas as matérias orgânicas, com particular interêsse nas biomembranas lipídicas (29/36).

A produção endógena de superóxidos e peróxidos de hidrogênio pode iniciar a peroxidação lipídica em membranas biológicas expostas. Os radicais de ácidos graxos formados dessa maneira podem reagir espontâneamente com o oxigênio formando, peroxiradical de ácido graxo e este pode propagar a peroxidação de mais moléculas de ácidos graxos pela retirada de átomos de hidrogênio para formar hidroperóxidos e novos radicais de ácidos graxos e assim por diante, levando a oxidação de muitas moléculas de ácidos graxos $(4,37,38)$.

Etapa inicial: interação do ácido graxo com radical hidroxila ou com o oxigênio singleto. Isto tem como consequência a perda de um átomo de hidrogênio do ácido graxo e liberação de um radical lipídico. Etapa 2: Este radical lipídico incorpora rapidamente uma ou mais moléculas de oxigênio e transforma-se em radical peróxido. Etapa 3: O radical peróxido interage com outra molécula de ac. graxo, retira o seu hidrogênio e origina um hidroperóxido e mais um novo radical lipídico livre formando-se, então, uma típica reação em cadeia:

$$
\begin{aligned}
& \text { 1. } \mathrm{LH}+\mathrm{OH}^{\mathrm{O}}-\mathrm{H}_{2} \mathrm{O}+\mathrm{L}^{\mathrm{O}} \\
& \text { 2. } \mathrm{L}^{\mathrm{O}}+\mathrm{O}_{2}-\mathrm{LOO}^{\mathrm{O}} \\
& \text { 3. } \mathrm{LOO}^{\mathrm{O}}+\mathrm{LH} \mathrm{LOOH}+\mathrm{L}^{\mathrm{O}}
\end{aligned}
$$

Como resultado da peroxidação de acidos graxos ocorre a produção de malondialdeído em tecidos submetidos à peroxidação dos ácidos graxos poliinsatura- dos dentro das membranas fosfolipídicas ${ }^{(3,39)}$. A vitamina $E$ ( $\alpha$-tocoferol) fornece átomos de hidrogênio para as membranas celulares e impede a reação em cadeia que se propaga nas membranas lipídicas ${ }^{(40 / 46)}$.

Alguns trabalhos populacionais e de laboratório são disponíveis para o entendimento do papel desta vitamina na proteção contra os radicais livres. No estudo realizado em nosso laboratório com ratos, onde foi provocado lesão de membrana por meio de isquemia mesentérica, observou-se que houve uma diminuição da produção de radicais livres no grupo de animais que receberam dieta suplementada com vitamina $\mathrm{E}$ sendo esta produção aumentada no grupo que recebeu dieta deficiente em vitamina E. Neste estudo, foi avaliada a proteção oferecida pela vitamina $\mathrm{E}$ à membrana, impedindo a translocação intestinal de Candida albicans, os resultados obtidos leveram a conclusão de que não houve influencia da vitamina $E$ na translocação intestinal ${ }^{(36)}$.

Doses terapeuticas de vitamina E se relacionaram com diminuição significativa do risco de doença coronariana em um grande estudo envolvendo cento e vinte mil pessoas, num seguimento de até oito anos $(47,48,49)$. A conclusão deste trabalho se apóia na hipótese de que a LDL oxidada é considerávelmente mais aterogênica do que a LDL nativa e que esta oxidação ocorre in vivo em animais e no homem. Animais recebendo antioxidantes mostraram diminuição de 30 a $80 \%$ nas taxas de progressão da lesão em estudos de aterosclerose experimental ${ }^{(50)}$.

Num estudo realizado no nosso laboratorio, Cordeiro et al, utilizando ratos alimentados com dieta normal e deficiente para os níveis de vitamina $\mathrm{E}$, e submetidos a nefrectomia subtotal, observou valores mais altos de substâncias reativas ao ácido tiobarbitúrico, sugerindo um importante papel dos radicais livres no desenvolvimento da insuficiência renal crôni$\mathrm{ca}^{(51)}$. Em outro experimento realizado no nosso laboratório demonstramos que a deficiência de vitamina $\mathrm{E}$ pode desencadear o processo de lipoperoxidação no fígado de ratos, conforme mostrado na Tabela IV.

Tabela IV - Lipoperoxidação em fígado de ratos, induzida pela deficiência da vitamina $\mathrm{E}$

\begin{tabular}{lccc}
\hline & Vitamina E $(\mu \mathrm{g} / \mathrm{g})$ & MDA $(\mathrm{nM} / \mathrm{mg}$ proteína $)$ & GSH $(\mu \mathrm{g} / \mathrm{g})$ \\
\hline Grupo Controle & $8,35 \pm 8,17 \mathrm{~A}$ & $0,54 \pm 0,06 \mathrm{~A}$ & $1396,9 \pm 143,43 \mathrm{~A}$ \\
Grupo Suplementado & $42,11 \pm 12,42 \mathrm{~A}$ & $0,67 \pm 0,06 \mathrm{~A}$ & $1427,3 \pm 319,91 \mathrm{~A}$ \\
Grupo Deficiente & $1,75 \pm 1,16 \mathrm{~A}$ & $2,95 \pm 0,27 \mathrm{~B}$ & $1146,8 \pm 252,16 \mathrm{~A}$
\end{tabular}

Letras diferentes, na mesma coluna, indicam diferença estatística para $p<0,05$. 
Vitamina C (Ácido ascórbico) - As plantas e a maioria dos animais podem sintetizar o ácido ascórbico a partir da glicose, porém humanos, primatas, cobaias não tem esta capacidade e por isso precisam receber a vitamina por meio dos alimentos. $\mathrm{O}$ ácido ascórbico in vivo é necessário como cofator para vários sistemas enzimáticos, sendo os mais conhecidos os da prolina-oxidase e lisina hidroxilase, envolvidos na biossíntese do colágeno. Ambos os sistemas contém o ferro no seu sítio ativo.

Do ponto de vista químico a propriedade mais interessante do ácido ascórbico é sua habilidade de atuar como agente redutor (doador de elétrons). Sua função de redutor (Fe III para Fe II) é importante na promoção da captação de ferro pelo intestino delgado. As observações de que o ácido ascórbico da dieta pode inibir a ação carcinogenética dos compostos nitrosos é atribuída à sua capacidade de reduzi-los às suas formas inativas.

O ácido ascórbico auxilía na detoxificação contra outros radicais orgânicos (por ex: aqueles formados pela radiação ionizante) provavelmente por processo de redução similar.

A solução aquosa de ácido ascórbico é estável a menos que ions de metais de transição estejam presentes, tais como o cobre, que catalisa sua rapida oxidação às expensas do oxigênio molecular. A oxidação do ácido ascórbico induzida por sais de cobre produz peróxido de hidrogênio e radicais hidroxila. A ação reinvindicada de degradação do DNA pelo ácido ascórbico e a destruição de celulas animais em cultura incluindo as neoplasicas pode eventualmente ser atribuída à formação dessas espécies de radicais em presença de ions de cobre na solução.

$\mathrm{O}$ ácido ascórbico reage rapidamente com $\mathrm{O}_{2}{ }_{2}^{-}$ e $\mathrm{HO}_{2}^{-}$e até mais rápido com $\mathrm{OH}^{-}$originando semihidroascorbato. Neutraliza ainda o oxigênio singlete, reduz radicais tiil e combina rapidamente com o ácido hipocloroso, um poderoso oxidante gerado no local de processos inflamatórios.

Vários efeitos negativos estão também sendo investigados: o ácido ascórbico pode reduzir FeIII para FeII e na presença de peróxido de hidrogênio estimula a formação de $\mathrm{OH}^{-}$por meio da Reação de Fenton. O efeito geral dependerá da concentração deascorbato presente uma vez que também neutraliza $\mathrm{OH}^{-}$. A administração de vitamina $\mathrm{C}$ para pacientes com sobrecarga de ferro tem provocado reações devido talvez à formação aumentada de $\mathrm{OH}^{-}$in vivo. ${ }^{(4,35)}$.
Por outro lado, estudo realizado nos USA com 864 pacientes portadores de adenoma colo retal mostrou que a administração de $\beta$-caroteno, vitamina $C$, vitamina $E$ isoladamente ou as tres vitaminas conjuntamente durante 4 anos, não resultou em nenhuma evidência de que essas vitaminas reduziram a incidência de adenomas e que portanto, não devem ser usadas na prevenção de câncer colo-retal ${ }^{(52)}$.

$\beta$-caroteno - O possível papel antioxidante do $\beta$-caroteno se deve ao decréscimo da formação do oxigênio singlete in vivo, e pode também reagir diretamente com radicais peróxido e alcóxidos, desta forma, interfere na reação em cadeia da peroxidação lipídica.

O $\beta$-caroteno é absorvido pelo homem através do intestino delgado, sendo utilizado como antioxidante. Por exemplo, grandes doses de $\beta$-caroteno diminuem a fotossenssibilidade de alguns pacientes com acúmulo anormal de porfirina, e tem sido proposto que altas ingestões de $\beta$-caroteno podem oferecer alguma proteção ao desenvolvimento de câncer defendendo as moléculas de DNA ${ }^{(4,44,53)}$. Estudos epidemiológicos em que $\beta$-caroteno pode estar envolvido na proteção contra AIDS e câncer, mostram que o seu efeito pode existir independente do seu papel como precursor da vitamina A. O $\beta$-caroteno agiria inibindo a transformação neoplásica induzida fisicamente ou quimicamente em células in vitro. $\mathrm{O}$ mecanismo pelo qual os carotenóides protegem os sistemas biológicos contra radicais livres seria inativando-os ${ }^{(44)}$.

Num estudo recente, realizado com indivíduos saudáveis sendo 38 não fumantes e 24 fumantes que receberam $20 \mathrm{mg}$ de $\beta$-caroteno ou placebo por um período de 4 semanas, observou-se que a peroxidação lipídica foi significativamente maior para o grupo de fumantes e só ocorreu sua redução quando recebeu a suplementação de $\beta$-caroteno no grupo dos fumantes, sugerindo que possa haver um efeito benéfico com a suplementação de $\beta$-caroteno sobre a peroxidação lipídica ${ }^{(54)}$.

Em outro estudo conduzido com vinte e nove mil, cento e trinta e três fumantes do sexo masculino, por períodos de 5 a 8 anos, na Finlândia, observou-se que entre 876 novos casos de cancer pulmonar, não houve redução na incidência entre homens que receberam $50 \mathrm{mg}$ de vitamina E diariamente. Surpreendentemente constatou-se maior incidência de cancer pulmonar entre os que receberam $20 \mathrm{mg}$ de $\beta$-caroteno, quando comparados aos que não haviam recebido ${ }^{(55)}$. 


\section{Glutationa}

O tripeptídeo glutationa (GSH), principalmente na sua forma reduzida, está presente na maioria das células e é o tíol (-SH) mais abundante no meio intracelular. Sua capacidade redutora está associada ao grupamento -SH presente na cisteína. A glutationa tem sido reconhecida como substrato para GSH-tranferases e GSH peroxidases, enzimas que catalizam as reações de detoxificação de compostos xenobióticos e da antioxidação de espécies reativas de oxigênio e radicais livres ${ }^{(4,56)}$. A concentração tissular de GSH pode ser regulada pela dieta e pelo estado nutricional ${ }^{(29)}$. Isto foi inicialmente demonstrado em estudos onde a concentração hepática de GSH era baixa durante períodos de jejum em ratos alimentados com dietas com baixos teores de proteína ou dietas deficientes em amino ácidos sulfurados. A concentração de GSH aumentou quando os animais foram realimentados ou quando receberam dietas suplementadas com aminoácidos sulfurados. Estes achados foram posteriormente confirmados em 1988 quando a concentração hepática de GSH diminuiu quando animais foram tratados com dietas contendo 4 e 7,5\% de proteína comparados com ratos tratados com dietas normoprotéicas $(15 \%)^{(57)}$.

Outro aspecto interessante na regulação da concentração tissular de GSH é a influência do estado nutricional nas enzimas de síntese de GSH. Tem sido observado que o estado nutricional anterior relativo a proteínas afeta o controle hepático da sintese de GSH. $\mathrm{O}$ estado nutricional pode influenciar as concentrações tissulares de GSH afetando o mecanismo de captação do GSH extracelular para tecidos extra-hepáticos via gama-glutamil transpeptidase e também o transporte plasmático de aminoácidos para dentro dos tecidos.

Alterações teciduais de GSH são relevantes para muitas doenças e intoxicações, especialmente para a desnutrição ${ }^{(58)}$.

As informações obtidas da regulação dietética e do estado nutricional do GSH tecidual pode ser clinicamente relevante, especialmente em relação aquelas doenças onde estão envolvidos simultâneamente a diminuição das concentrações teciduais de GSH e a ocorrência de estresse oxidativo. Um fator contributivo comum para maior mortalidade e morbidade é a desnutrição. Muitos pacientes sofrem de desnutrição protéico-calórica secundária, por exemplo, por queimaduras, doenças crônicas digestivas, alcoolismo, AIDS ou câncer. Muitos sinais clínicos da desnutrição seriam resultado do enfraquecimento dos sistemas de defesa, incapazes de detoxificar um produção aumen- tada de radicais livres. Crianças desnutridas que morrem logo após internação em hospitais tem baixos níveis de GSH, vitamina E e Zinco e ao mesmo tempo altos níveis de ferritina e ferro intrahepático ${ }^{(57)}$. Além disso, crianças desnutridas frequentemente requerem medicamentos e oxigênioterapia para tratamento e são propensos à infecção oportunísticas. Uma estratégia usada para restabelecer os níveis de GSH para antioxidação e sistema imunológico antes dos tratamentos medicamentosos poderia aumentar a eficiência dos agentes terapêuticos sem causar lesões teciduais por oxidação. Demonstrou-se que a as concentrações de GSH tanto hepáticas como pulmonares podem ser restabelecidas com a suplementação oral de um unico substrato, a cisteína, sem o suporte nutricional completo. Além disso, a tentativa de reabilitação imediata com dietas ricas em calorias e proteínas poderiam ser contraindicadas. Tem sido mostrado que a imediata reabilitação com dietas altamente energéticas contendo acidos graxos poliinsaturados, ferro ou hidrolisados de proteína frequentemente resultam em altas taxas de mortalidade em crianças com "kwashiorkor" (35,57,58).

A maior parte da glutationa livre in vivo está sob a forma de GSH ao invéz de GSSG, porém mais de $2 / 3$ da glutationa celular total pode estar presente em formas mixtas, tais como cisteína, coenzima A e o radical-SH dos resíduos da cisteína do GSH a GSSG às custas do peróxido de hidrogênio.

Jordão Jr et al. avaliaram os níveis de glutationa hepática após a administração aguda de etanol. Foi possivel observar aumento na sua concentração após esta situação de estresse oxidativo ${ }^{(59)}$.

\section{Proteção por Sequestração de Íons Metálicos}

Íons de metais de transição como o ferro e o cobre estão envolvidos em várias reações de radicais livres e frequentemente levam a geração de espécies muito reativas a partir de espécies menos reativas ${ }^{(60)}$. No caso do ferro, já vimos que o ferro ligado a proteínas não é normalmente disponível para estimular reações de radicais, a menos que o ferro esteja liberado pelas proteínas. Desta forma, seu transporte e armazenamento (ferritina e transferrina) proporciona uma defesa antioxidante. Metalotioneínas são proteínas de baixo peso molecular encontradas no citosol de células eucariocíticas, especialmente no fígado, rins e intestino, são muito ricas em enxôfre e tem a habilidade de ligar íons metálicos como: $\mathrm{Zn}^{2+}, \mathrm{Cu}^{+}, \mathrm{Cd}^{2+}, \mathrm{Hg}^{2+}$. A ligação é conseguida pela associação de cisteínagrupos SH com o íons metálicos ${ }^{(2,3,4)}$. 


\section{CONDIÇÕES CLÍNICAS E OS RADICAIS LIVRES}

Talvez o principal aspecto resultante de intensa pesquisa nos últimos anos tenha sido o reconhecimento de que os metabolitos do oxigênio altamente reativos são parte integrante do metabolismo normal, incluindo a geração oxidativa de energia pelas mitocôndrias da cadeia respiratória, a detoxificação dos xenobióticos pelos citocromos, a função fagocítica contra microorganismos, o metabolismo do acido araquidônico na produção de prostaglandinas e leucotrienos e mesmo a ovulação e fertilização ${ }^{(8,25,32)}$.

Assim, acredita-se que mesmo em presença de grande número de mecanismos potentes de defesa antioxidantes dentro das células, muitas vezes, estes podem ser superados pelos fatores oxidantes, resultando em lesões teciduais por meio da peroxidação das membranas lipídicas de células e organelas, a desnaturação funcional (enzimas) de proteínas estruturais, lesões mutagenicas ou letais dos ácidos nucléicos e a desnaturação de componentes polissacarídeos de componentes do interstício de membranas basais ${ }^{(25,61)}$. Consequentemente, esta toxicidade local dos radicais livres e outros produtos tóxicos do oxigênio constitue a via comum final da lesão tecidual em uma variedade de doenças ${ }^{(60,62)}$.

\section{Toxicidade Química e Xenobiótica}

Vários agentes exógenos exercem seus efeitos tóxicos no organismo por meio de geração secundária de oxidantes pela sua metabolização ${ }^{(63)}$. O exemplo classico é a geração secundária de superóxidos pelo ciclo redox do radical livre paraquat, que é gerado pelo catabolismo do herbicida paraquat pelo citocromo P-450. Outro exemplo comum, do ponto de vista clínico, é a toxicidade dos agentes quimioterápicos (toxicidade pulmonar dada por bleomicina, cardíaca pelo adriamicina; toxicidade aguda e mutagenicidade a longo prazo (carcinogênese) do cigarro e dos poluentes do ar e provávelmente a toxicidade hepática, do sistema nervoso central e cardíaca do etanol. Recentemente a geração metabólica do $\mathrm{MPP}^{+}$ (1-metil-4-fenilpiridinium) radical livre do opiáceo MPTP (1,2,3,6-tetrahidro-1-4-fenilpiridina) pela monoamino-oxidase no SNC, mostrou uma degeneração da substancia nigra produzindo uma doença semelhante à Doença de Parkinson em macacos e mesmo em humanos consumidores dessa droga ilegal. Esta descoberta não só propiciou um modelo útil, facilitando o estudo daquela doença como também mostrou mais uma vez a possibilidade da ligação entre sua causa e agentes ambientais. Propiciou também o estudo de possíveis inibidores da monoaminooxidase retardando o aparecimento da doença. Em geral, entretanto, o melhor entendimento desses mecanismos de toxicidade clínica e xenobiótica não tem sido diretamente tranferida para modificações significativas das praticas terapêuticas. Por exemplo: a toxicidade dos quimioterápicos pode ser amenizada pela terapia antioxidante em muitos casos, porém, a atividade tumoricida também é limitada sem melhora evidente do índice terapêutico (25).

A ação tóxica e carcinogênica das nitrosaminas é conhecida, e no estudo da administração de uma dose aguda de dietilnitrosamina (DEN) observou-se que a deficiência de vitamina $\mathrm{E}$ na dieta de ratos permitiu um dano tóxico maior do que nos grupos de animais alimentados com dietas normal e suplementada para vitamina $\mathrm{E}^{(64)}$.

\section{Lesão da Reperfusão Pós Isquemia}

Quando um tecido é exposto ao processo de isquemia, a falta de oxigênio e a depleção de energia leva à várias alterações bioquímicas incluindo formação de metabólitos citoplasmáticos e má função dos sistemas de transporte de membrana. Esta sequência de reações químicas pode levar à necrose. Sabe-se que os prejuízos causados pela isquemia são diretamente proporcionais ao tempo de duração desta ${ }^{(3,5,65)}$.

Estudos têm demonstrado que a maioria dos prejuízos que ocorre aos tecidos isquêmicos, acontece após a reperfusão e uma pequena parte, durante a isquemia, a isto chama-se lesão de reperfusão ${ }^{(25,36,65)}$. Esta lesão é causada por diversas reações químicas, que ocorrem após o retorno de sangue oxigenado para o tecido isquêmico. Estas reações resultantes da reperfusão, envolvem os metabólitos reativos do oxigênio $^{(36,66,67,68)}$.

A aplicação de terapia anti-oxidante em modelos animais de lesão pós-isquêmica e em experimentos clínicos, tem levado a conclusão opostas, desde benefícios espetaculares como até nenhum efeito mensurável ${ }^{(69)}$. Diferentes abordagens podem explicar tais achados, porém aceita-se que somente o componente de reperfusão é controlável e passível de benefícios com a terapia antioxidante ${ }^{(69,70)}$.

\section{Condições Inflamatórias}

Vários mecanismos fundamentais da inflamação envolvem a geração de radicais livres. A síntese 
de prostaglandinas e leucotrienos a partir do ácido aracdônico constituem duas séries de mediação dos radicais livres na lipoperoxidação que pode iniciar ou ser disparada por radicais livres adjacentes. A proteção contra microorganismos exercida pelos fagócitos teciduais e pelos neutrófilos circulantes é facilitada pela geração inicial de superóxido por uma membrana altamente especializada contendo uma oxidase associada e a subsequente geração de ácido hipocloroso e secundariamente clorameinas reativas pela mieloperoxidase.

Evidências recentes sugerem que a enzima xantina-oxidase geradora de radicais livres, localizada na superfície luminal de celulas endoteliais microvasculares pode agir como ativador do mecanismo de aprisionamento, ingestão e morte de microorganismos circulantes dentro do sistema reticulo-endotelial. Neste local ela pode ser ativada rapidamente pela proteólise ainda que inicial e estimulada por citocinas circulantes(fator de necrose tumoral, interleucina-3), bactérias, endotoxinas ou outros estímulos inflamatórios de modo semelhante à cascata da coagulação, o sistema de complemento ou o eixo renina-angiotensina sem esperar uma modificação da expressão genética ${ }^{(25,60)}$.

Apesar do papel significativo exercido pelos radicais livres derivados do oxigênio, no processo inflamatório, as implicações clínicas diretas desse conhecimento são ainda surpreendentemente pequenas. Isto é parcialmente devido ao fato de que ainda não se descobriu a maneira adequada de aplicar os antioxidantes em um antígeno específico ou no local adequado.

Assim, as tentativas de injeção de antioxidantes dentro das articulações de pacientes com artrite reumatóide tem sido, a rigor, desapontadoras.

\section{Lesões Degenerativas}

A peroxidação lipídica têm sido implicada na patogênese de muitas desordens degenerativas, incluindo o diabetes mellitus natural ou quimicamente induzido. Os resultados do estudo onde suplementou-se a dieta de ratos com vitamina $E$ induzindo o diabetes com estreptozotocina, levaram a conclusão de que a estreptozotocina leva a quadro diabético e pró-oxidativo mesmo na presença de alta concentração de vitamina E, conforme mostrado na Tabela $\mathrm{V}^{(72)}$.

O possível papel dos antioxidantes na Artrite Reumatóide e Osteoartrite tem sido muito discutido, assim como, possível importância de oxidantes na carcinogênese por produtos químicos e radiações.

Aterosclerose - A modificação da LDL pode ser obtida pela sua oxidação por espécies reativas de oxigênio, na presença de metais de transição, principalmente cobre e ferro. O processo inicia-se com a peroxidação dos ácidos graxos polinsaturados da LDL, o que pode ocorrer em qualquer membrana biológica exposta $\left(\mathrm{RH}+\mathrm{OH}^{*}=>\mathrm{H}_{2} 0+\mathrm{R}^{*}\right)$. A peroxidação lipídica, se não for bloqueada, pode ter atividade sequencial pois os radicais assim formados reagem novamente com o oxigênio formando um peroxirradical de ácido graxo $\left(\mathrm{R}^{*}+\mathrm{O}_{2}=>\mathrm{ROO} *\right)$ o qual reage com um ácido graxo, perfazendo uma reação em cadeia e formando aldeidos, principalmente malonaldeido ( $\mathrm{ROO}^{*}+\mathrm{RH}=>\mathrm{ROOH}+\mathrm{R}^{*}$ ). Tais alterações a tornam mais citotóxica para as células endoteliais e permitem a sua captação pelo receptor alternativo, diferente do clássico B/E. Esse receptor alternativo, mais rápido, poderia explicar a ausência do "feed-back" negativo e o grande acumulo de colesterol intracelular, em pacientes portadores de deficiência ou ausência de receptores B/E. Ainda, em relação a aterosclerose, recentes relatos a respeito da peroxidação da LDL circulante na formação das placas que facilitaria sua captação pelos fagócitos sub-endoteliais e formação das células espumosas ${ }^{(2,28)}$.

A ingestão de $50 \mathrm{mg}$ de $\beta$-caroteno como antioxidante, em dias alternados, tal como a aspirina, poderia levar a efeito protetor contra um segundo evento cardiovascular.

Por fim existem dados evidenciando que o processo de envelhecimento ao nível celular pode estar relacionado ao acúmulo de lesões mediadas por radicais livres oxidantes, e os antioxidantes têm sido estudados como possível arma no controle do processo ${ }^{(25,35,50,73)}$.
Tabela V - Peroxidação lipídica no diabetes, induzido pela estreptozotocina, em ratos, suplementados com vitamina E e que não receberam insulina

\begin{tabular}{lcc}
\hline Grupo Diabético & MDA (nM/mg proteína) & Glicemia $(\mathrm{mg} \%)$ \\
24 horas & $0,846 \pm 0,337$ & $447,50 \pm 115,77$ \\
1 semana & $0,628 \pm 0,164$ & $286,57 \pm 123,42$ \\
2 semanas & $0,670 \pm 0,110$ & $314,42 \pm 101,57$ \\
Grupo Controle & MDA (nM/mg proteína) & Glicemia (mg\%) \\
24 horas & $0,073 \pm 0,017$ & $80,30 \pm 11,77$ \\
\hline
\end{tabular}




\section{ANTIOXIDANTES NA PRÁTICA NUTRICIONAL}

Os radicais livres tem sido arrolados em processos nosológicos dos diferentes orgãos e sistemas, destacando-se as doenças neurodegenerativas, doenças inflamatórias crônicas, doenças cardiovasculares e neoplásicas, muito embora, a expectativa clínica não corresponda ao entusiasmo teórico. Evoluímos nosso conhecimento em relação à lesão de reperfusão sendo que o uso de soluções com alopurinol e sua associação com outros antioxidantes como glutationa, melhoram indubitávelmente a preservação de orgãos a serem transplantados, sendo hoje praticamente inadmissível a sua não utilização. Todavia, esperava-se uma verdadeira revolução na terapêutica do infarto do miocárdio e, entretanto, os resultados são desapontadores. Nas cirurgias eletivas, com circulação extracorpórea, a reperfusão com antioxidantes tem obtido resultados mais promissores sendo que estudos estão sendo delineados visando a reperfusão do SNC pós acidente vascular cerebral ou mesmo parada cardíaca, na tentativa de modificar um quadro até agora tido como irreversível. As tentativas de intervenção nas doenças inflamatórias crônicas tem sido efetuadas mas os resultados ainda são controversos. A elevação da concentração de ácido ascórbico tem sido associada a uma melhora da função pulmonar e diminuição da hiperreatividade brônquica, mas juntamente com a aerosol-terapia com antioxidantes como GSH e N-acetilcisteína, necessitam melhores esclarecimentos.

Quanto ao uso de vitaminas antioxidantes, um vasto e controverso campo se descortina. As vitaminas $\mathrm{C}, \mathrm{E}$ e o $\beta$-caroteno, mais recentemente os dois últimos, tem sido apontadas como atuantes na prevenção de doenças crônicas, doenças cardiovasculares e câncer, principalmente de pulmão e cólon. A literatura nessa área se destaca pelos resultados dispares em experimentos semelhantes, sendo que, em alguns casos, talvez a ânsia em beneficiar comprometa o necessário rigor cientifico das investigações. Tem sido sugerido que as lesões carcinogênicas do DNA podem ser prevenidas pela remoção dos radicais livres produzidos pelo metabolismo normal. Para as doenças cardiovasculares, supõe-se que as vitaminas antioxidantes, especialmente a vitamina $\mathrm{E}$ e o $\beta$-caroteno, possam inibir a oxidação das LDL para a sua forma mais aterogênica e assim, preservar o endotélio. Os radicais livres estão envolvidos numa ampla gama de processos patológicos, porém não necessariamente de forma que sua ação seja determinante, decisiva dos eventos bioquímicos ou biológicos. E se são importantes, como analisar um antioxidante em combinação com os vários fatores também atuantes? A existência de múltiplos estágios na carcinogênese certamente confunde a correta análise da função de um antioxidante como anticarcinogênico. Assim, estudos de maior abrangência devem ser ainda realizados para definir melhor a participação do estresse oxidativo na produção do dano, conquanto sinais da sua importância venham nítidamente se avolumando. Também, pouco pode ser dito em relação a preponderância deste ou daquele antioxidante; é provável que um delicado balanço entre os vários antioxidantes, agindo por um tempo mais prolongado, seja mais importante para a capacidade total de proteção do sistema do que a atividade de uma só molécula ou enzima. Existem fortes evidências de que o câncer e as doenças cardiovasculares possam ser prevenidos ou retardados por mudanças alimentares tais como redução da ingestão de gorduras e aumento do consumo de frutas, grãos e vegetais. Vários produtos desta dieta podem agir como antioxidantes e assim explicar parte do efeito de uma dieta saudável, atuando durante toda uma vida. Se, associado a isso, a ingestão de vitaminas antioxidantes promove a saúde e evita ou retarda o aparecimento de doenças ainda está por ser confirmado. Todavia, o acúmulo de evidências da participação dos radicais livres na patogênese das doenças que mais contribuem para reduzir a qualidade e a expectativa de vida, é sem dúvida aspecto positivo e pode levar a novos procedimentos terapêuticos. Como trata-se de um campo onde os conhecimentos partem de mecanismos básicos e ainda não totalmente aplicados; o futuro pode ser promissor e as investigações excitantes. Enquanto isso pode-se oferecer os nutrientes com possível efeito de neutralização dos radicais livres sob forma fisiológica dos alimentos em quantidades suficientes para evitar qualquer risco de deficiência provocado ou não por doenças secundárias.

Para efeito de exemplo a Tabela VI mostra a composição de uma dieta geral utilizada no nosso país e a oferta de cada um dos nutrientes antioxidantes. 
Tabela VI - Exemplo de dieta geral

\begin{tabular}{|c|c|}
\hline Refeição & Quantidade \\
\hline \multicolumn{2}{|l|}{ Desjejum } \\
\hline Café & $60 \mathrm{~g}$ \\
\hline Açúcar & $20 \mathrm{~g}$ \\
\hline Pão francês & $50 \mathrm{~g}$ \\
\hline Margarina & $10 \mathrm{~g}$ \\
\hline Mamão & $100 \mathrm{~g}$ \\
\hline Queijo & $45 \mathrm{~g}$ \\
\hline \multicolumn{2}{|c|}{ Complementar da manhã } \\
\hline Maçã & $150 \mathrm{~g}$ \\
\hline \multicolumn{2}{|l|}{ Almoço } \\
\hline Arroz & $120 \mathrm{~g}$ \\
\hline Feijão & $60 \mathrm{~g}$ \\
\hline Carne & $60 \mathrm{~g}$ \\
\hline Cenoura & $75 \mathrm{~g}$ \\
\hline Couve & $100 \mathrm{~g}$ \\
\hline Alface & 2 folhas \\
\hline Tomate & 3 fatias \\
\hline Óleo de soja & $7,5 \mathrm{~g}$ \\
\hline Banana & 1 unidade média \\
\hline \multicolumn{2}{|c|}{ Complementar da tarde } \\
\hline Bolacha & $26 \mathrm{~g}$ \\
\hline Suco de laranja & $250 \mathrm{~g}$ \\
\hline Açúcar & $10 \mathrm{~g}$ \\
\hline \multicolumn{2}{|l|}{ Jantar } \\
\hline Arroz & $120 \mathrm{~g}$ \\
\hline Feijão & $60 \mathrm{~g}$ \\
\hline Carne & $60 \mathrm{~g}$ \\
\hline Beterraba & $80 \mathrm{~g}$ \\
\hline Brócolis & $150 \mathrm{~g}$ \\
\hline Óleo de soja & $7,5 \mathrm{~g}$ \\
\hline Abacaxi & $100 \mathrm{~g}$ \\
\hline \multicolumn{2}{|l|}{ Ceia } \\
\hline Bolacha & $28 \mathrm{~g}$ \\
\hline Suco de laranja & $200 \mathrm{~g}$ \\
\hline Açúcar & $10 \mathrm{~g}$ \\
\hline \multicolumn{2}{|c|}{ Valor Nutricional da dieta apresentada } \\
\hline Calorias & 2340 Kcal \\
\hline Proteína & $86 \mathrm{~g}$ \\
\hline Lípides & $69 \mathrm{~g}$ \\
\hline Carboidratos & $344 \mathrm{~g}$ \\
\hline Zinco & $16 \mathrm{mg}$ \\
\hline Vitamina C & $424 \mathrm{mg}$ \\
\hline Vitamina A & $4200 \mathrm{ER}$ \\
\hline Vitamina $\mathrm{E}$ & $28 \mathrm{mg}$ \\
\hline
\end{tabular}


VANNUCCHI $\mathrm{H}$ et al. Role of nutrients on lipid peroxidation and antioxidant defense system . Medicina, Ribeirão Preto, 31: 31-44, jan./march 1998.

ABSTRACT: Reactive oxygen species are generated in aerobic metabolism and can damage lipids, proteins, carbohydrates and DNA. These potentially deleterious reactions are controlled by a system of enzymatic and non-enzymatic antioxidants which eliminates prooxidants and scavenge free radicals. This revision focuses the role of particular nutrients in lipid peroxidation and antioxidant defense system. Emphasis was placed on mechanisms for damage and protection, as well implications in human healthy issues

UNITERMS: Antioxidants. Nutrition. Lipid Peroxidation. Free Radicals.

\section{REFERÊNCIAS BIBLIOGRÁFICAS}

1 - BAST, A. et al. Oxidants and antioxidants: State of the art. Am. J. Med., 91, 2-13, 1991.

2 - HALLIWEL, B.; et al. Free radicals, antioxidants, and human disease: Where are we now? J. Lab. Clin. Med., 119: 568-620, 1992.

3 - PERROTA, V. \& SHINAIDER, A. Radicais livres de oxigênio: Importância na fisiopatologia das lesões isquêmicas viscerais. An. Acad. Med., 152 (1), 22-27, 1992.

4 - HALLIWEL, B. \& GUTTERDGE, J. M. C. Free Radicals in Biology and Medicine. 2th ed. Oxford, Clarenton Press, 1989.

5 - FABRIS, V. E. Morte e necrose celular. Medicina, Ribeirão Preto, 25: 143-152, 1991.

6 - HARRIS, E. D. Cooper as a cofator and regulator of cooper, zinc, superoxide-dismutase. J. Nutr. 122: 636-640, 1992.

7 - DIPLOCH, A. Antioxidant nutrients and disease prevention an overview. Am. J. Clin. Nutr., 53, 189-193, 1991.

8 - GOODE, H. F. \& WEBSTER, N. R. Free radicals and antioxidants in sepsis. Crit. Care Med., 21 (1): 1770-1776, 1993.

9 - ALLEN, R. G. \& VONKAHAJ, V. S. Oxidants and antioxidants in development and differentiation. J. Nutr.,122: 631-635, 1992.

10 - JONES, D. P. et al. Impact of nutrients on cellular lipid peroxidation and antioxidant defense system. Fundam Appl Tocoxicol 26: 1-17, 1995.

11 - HALLIWELL, B. et al. The caracterization of Antioxidants. Food Chem. Toxic., 33 (7), 601-617, 1995.

12 - MARUBAYASHI, S.; et al. The protective effect of administred tocofherol against hepatic damage caused by isquemiareperfusion or endotoxemia. Ann. N. Y. Acad. Sciences, 570, 208-218, 1989.

13 - STEINBERG, D. Antioxidants and coronary heart disease. New Engl. J Med. 328 (20), 1487-1489, 1993.

14 - PITT, R. M.; et al. A tungesten- suplemented diet delivered by transplacental and breast-feeding routes lowers intestinal xantine-oxidase activity and affords cytoprotection in isquemia-reperfusion injury to the small intestine. J. Ped. Surg., 26 (8), 930-935, 1991.

15 - CORDEIRO, M.B.C. et al. Aumento da atividade da superóxido dismutase no eritrócito de retos deficientes em vitamina $\mathrm{E}$ e submetidos a nefrectomia subtotal. In: Resumos, IV Congresso da Sociedade Brasileira de Alimentação e Nutrição (SBAN), São Paulo, p. 135, 1996.

16 - SOUTHORN, P.A. \& POWIS, G. Free radicals in medicine. In: chemical nature anal biologia reactions. Mayo Clin. Prod., 63 (4), 300-408,1988.

17 - ASCHERIO, A. et al. Correlations of vitamin A and intakes with the plasma concentrations of carotenoids and tocopherols among american men and women. J. Nutr., 122,17921801,1992

18 - CANTONI, L. et al. Effects of iron and hemopoproteins on hydrogen peroxide-supported styrene oxidation to styrene oxide. Experientia, 38, 1192-1194, 1982.

19 - KOK, F. J. et al. Do antioxidants and polynsaturated fatty acids have a combined association with coronary atherosclerosis? Atherosclerosis, 31, 85-90, 1991.

20 - MENZEL, D. B. Antioxidant vitamin and prevention of lung disease. Ann. N. Y. A. Sci. 669, 141-155, 1992.

21 - SALONEN, J. T. et al. Interactions of serum cooper, selenium, annd low density lipoprotein cholesterol in atherogenesis. B.M.J., 302 (30), 756-760,1991.

22 - CHOW, C.S. Vitamin E and oxidative stress. Free Radic. Biol. Med. , 11, 215- 232, 1991.

23 - TAYLOR, C. G. \& BRAY, T. M. Effect of hiperoxia on oxigen free radical defense enzymes in lung of zinc deficient rats. J. Nutr. 121, 460-466, 1991.

24 - MAcCAY, P. B. et. al. An update on antioxidant theory: spin trapping of the trichloromethyl radicals in vivo. Ann. N. Y. Acad. Sciences, 393, 23-32, 1982.

25 - BULKLEY, G. B. Free radicals and order reactive oxigen metabolites: Clinical relevance and the therapeutic efficacy of antioxidant therapy. Surgery, 113, 479-483, 1993. 
26 - STADMAN, E. R. Protein oxidation and aging. Science, 257, 1220-1224, 1992

27 - YOSHIKAWA, T.; et al. Role of oxygen - derived free radicals in gastric mucosal injury induced by ischemia or ischemia - reperfusion in rats. Free Rad. Res. Comms., 7, 285-291, 1989.

28 - BENDICH, A. Vitamins and immunity. J. Nutr., 122, 601-603, 1992.

29 - VANNUCCHI, $\mathrm{H}$., et al. Effect of different dietary levels of vitamin $\mathrm{E}$ on lipid peroxidation in rats. Arch Latinoam Nutr 47, 34-37, 1997.

30 - a -WILLS, E. D. Lipid peroxide formation in microsomes - The role of non - haem iron. Biochem. J. 113, 325-332, 1969.

31 - WILLS, E.D. Lipid peroxideformation in microsomes Biochem. J. 113,333-341, 1969.

32 - FREEMAN, B. A. \& CRAPO, J. D. Biology of disease - Free radicals and tissue injury. Lab Invest, 47, 412-426, 1982.

33 - BUEGE, J. A. \& AUST, S. D. Microssomal lipid peroxidation Methods Enzym., 105, 302-310, 1985.

34 - NIKI, E.; et al. Membrane damage due to lipid oxidation. Am. J. Clin. Nutr., 53, 201s-205s, 1991.

35 - YU, B. P. Cellular defenses against damage from reactive oxygen species. Physiol Rev. 74 (1), 139-162, 1994.

36 - MORANDI, M. V.; et al. Estudo da translocação de Candida albicans provocada pela isquemia mesentérica em ratos e 0 efeito protetor da vitamina E. In: Resumos, IV Congresso da Sociedade Brasileira de Alimentação e Nutrição (SBAN), São Paulo, p. 151, 1996.

37 - ABBEY, M.; et al. Antioxidant vitamins and low-density- lipoprotein oxidation. Am. J. Clin. Nutr., 53, 201-205, 1991.

38 - JIALAL, I. \& GRUNDY, S. D. Influence of antioxidant vitamins on LDL oxidation. Ann. N. Y. Acad. Sciences, 669 (30), 237-248, 1992.

39 - MYERS, C. E. \& TRAVIS, E. Effect of tocopherol and selenium on defenses against reactive oxigen species and their effect on radiation sensitivity. Ann. N. Y. Acad. Sciences, 393, 1220-1224, 1982

40 - SHILS, M. E. \& YOUNG, V. R. Modern Nutrition in Health and Disease. 7th ed. Edit. Lea \& Febiger, Philadelphia, P. A., U. S. A. !988.

41 - VILE, G. F. \& WINTERBURN, C. C. Inhibition of adriamycin promoted microsomal lipid peroxidation by b-carotene, atocofherol and retinol high and low oxigen partial pressure. FEBS.LETT, 238 (2), 353-356, 1988.

42 - ESTEUBAUER, $\mathrm{H}$; ; et al. The role of vitamin $\mathrm{E}$ and carotenoids in preventing oxidation low density lipoproteins. Ann. N. Y. Acad. Scienses, 570, 254-267, 1989.

43 - PETTY, M. A.; et al. Effect of a cardioselective tocofherol analogue on reperfusion injury in rats induced by myocardial isquemia. Eur. J. Pharmacol, 192, 383-388, 1991.
44 - SIES, H. et al. Antioxidants function of vitamins: Vitamins $E$ and $\mathrm{C}$, -carotene and other carotenoids. Ann. N. Y. Acad. Sciences, 669, 7-20, 1992.

45 - Vitamin E supplementation enhances immune response in the elderly. Nutr Rev. 50 (3), 85-87, 1992.

46 - TIIDUS, P. M., et al. Effects of vitamin E status and exercise training on tissue lipid peroxidation based on two methods of assessment. Nutr Res, 13, 189-193, 1993.

47 - MAcINTOSH, M. K.; et alli. Vitamin E alters hepatic antioxidant enzymes in rats treated with dehydroepiandrosterone (DHEA). J. Nutr., 123, 216-224, 1993

48 - RIMM, E. B.; et al. Vitamin E consumption and the rise of coronary heart disease in men. N Engl. J. Med., 328 (20), 1450-1456, 1993

49 - STAMPFER, M. J.; et al. Vitamin E consuption and the risk of coronary disease in women. N Engl. J. Med., 328 (20), 1444-1449, 1993

50 - STEINBERG, D. Antioxidants in the prevention of human atherosclerosis. Circulation, 85(6), 2337-2344, 1992.

51 - CORDEIRO, M.B.C. et al. Peroxidação lipídica em ratos deficientes em vitamina $E$ e submetidos à nefrectomia subtotal. In: Resumos, IV Congresso da Sociedade Brasileira de Alimentação e Nutrição (SBAN), São Paulo, p. 149, 1996.

52 - GREENBERG et al. A clinical trialof antioxidant vitamins to prevent coloretal adenoma. N. Engl. J. Med., 331(3), 18990, 1994

53 - WOLF, G. Retinoids and carotenoids as inhibitors of carcinogenesis and inducers of cell - cell communication. Nutr Rev. 50, 270-274, 1992.

54 - ALLARD, J.P. et al. Effects of b-caroteno supplementation on lipid peroxidation in humans. Am. J. Clin. Nutr., 59, 884 890, 1994.

55 - HEINONEM, O. P. et al. The effect of vitamin E and beta carotene on the incidence oof lung cancer and others cancer in male smokers. N Engl. J. Med. 320 (14), 1029-35,1994.

56 - PRYOR, W. Free radical biology: Xenobiotics, cancer and aging. Ann. N. Y. Acad Sci 393: 11-23, 1982.

57 - BRAY, T. M. \& TAYLOR, C. G. Tissue glutathione, nutrition and oxidative stress. Can. J. Pharmacol. 71, 746-751, 1993.

58 - HAGIWARA, K.; et al. Kidney injury induced by lipid peroxide produced by vitamin $\mathrm{E}$ deficiency and GSH depletion in rats. J. Nutr. Sci. Vitaminol 37, 99-107, 1991.

60 - JORDÃO JR., A.A. et al. Níveis hepáticos da glutationa e atividade sérica da carnosinase em ratos recebendo uma dose aguda de etanol. In: Resumos, IV Congresso da Sociedade Brasileira de Alimentação e Nutrição (SBAN), São Paulo, p. 148, 1996.

60 - CROSS, C. E.; et al. Oxigen radicals and human disease. Ann. Intern Med, 107, 526-545, 1987. 
61 - KUBOW, S. Lipid oxidation products in food and atherogenesis. Nutr. Rev, 51 , 33-40, 1993.

62 - MACHLIN, L. J. \& BENDICH, A. Free radical tissue damage: protective role of antioxidant nutriets. FASEB J., 1, 441445, 1987.

63 - JORDÃO JR., A.A. et al. Lipoperoxidação no fígado de ratos induzida por dose aguda de etanol. In: Resumos, IV Congresso da Sociedade Brasileira de Alimentação e Nutrição (SBAN), São Paulo, p. 148, 1996.

64 - CHIARELLO P.G. et al. Efeito da administração de uma dose aguda de dietilnitrosamina (DEN) sobre ratos suplementados com vitamina E. In: Resumos, IV Congresso da Sociedade Brasileira de Alimentação e Nutrição (SBAN), São Paulo, p. 141, 1996.

65 - KERRIGAN, C. L. \& STOLAND, M. A. Ischemia reperfusion injury: A review. Microsurgery, 14, 165-175, 1993.

66 - GRANGER, D.N.; et al. Superoxide radicals in feline intestinal isquemia. Gastroenterology, 81, 22-29, 1981

67 - PUNCH, J.; et al. Xanthine-oxidase: Its role in the no-reflow phenomenon. Surgery, 111, 169-176, 1992.

68 - ZIMMERMAN, B. J. \& GRANGER, N. Reperfusion Injury. Surg. Clin. North Am, 72 , 65-83, 1992.
69 - SERBINOVA, E.; et al. Palm oil vitamin E protects against isquemia/reperfusion injury in the isolated perfused lagendorff heart. Nutr. Res., 12, 203-221, 1991.

70 - SALIM, A. W. S. Gastric mucosal cytoprotection in the rat by scavenging oxigen - derivated free radical. Am. J. Med. Sciences, 302, 287-291, 1991.

71 - KLEIN, H. H., et al. Failure of chronic, high-dose, oral vitamin $\mathrm{E}$ treatement to protect the isquemic, reperfused porcine heart. J. Mol. Cell. Cardiol 25, 103-112, 1993.

72 - ARAÚJO, W.F. et al. Peroxidação lipídica no diabetes induzido pela estreptozotocina. Efeito da suplementação com a vitamina E. In: Resumos, IV Congresso da Sociedade Brasileira de Alimentação e Nutrição (SBAN), São Paulo, p. 150, 1996.

73 - STEINBERG, D. et al. Beyond cholesterol: Modification of low density lipoprotein that increase its atherogenicity. N Engl. J. Med., 320 (14), 915-924, 1989.

Recebido para publicação em 30/01/1998

Aprovado para publicação em 25/02/1998 